\title{
Cost-Benefit Analysis of Endocrine Therapy in the Adjuvant Setting for Postmenopausal Patients with Hormone Receptor-Positive Breast Cancer, Based on Survival Data and Future Prices for Generic Drugs in the Context of the German Health Care System
}

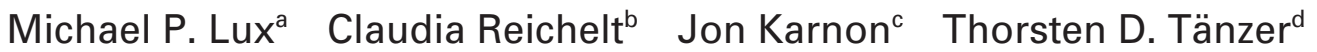 \\ Dragan Radosavac ${ }^{\mathrm{e}}$ Peter A. Fasching ${ }^{\mathrm{a}}$ Matthias W. Beckmann ${ }^{\mathrm{a}} \quad$ Falk C. Thiel $^{\mathrm{a}}$ \\ aUniversity Breast Center for Franconia, Frauenklinik des Universitätsklinikums Erlangen, Friedrich-Alexander Universität Erlangen- \\ Nürnberg, Erlangen, ${ }^{b}$ Pharmacoeconomy, Nürnberg, Germany, 'Discipline of Public Health, School of Population Health and Clinical \\ Practice, University of Adelaide, Australia, ${ }^{d}$ Medicornea Ltd., Neuss, ${ }^{e}$ Dept. of Internal Medicine II/Cardiology, Stiftung Krankenhaus \\ Bethanien für die Grafschaft Moers, Germany
}

\section{Keywords}

Letrozole $\cdot$ Anastrozole $\cdot$ Tamoxifen · Cost-effectiveness · QALY · BIG 1-98 · ATAC

\section{Summary}

Background: Cost-effectiveness analyses have focused on aromatase inhibitors (Als), but the results are inconsistent and disease-free survival has often been extrapolated to overall survival. The present study calculates the cost-effectiveness of 5 years of letrozole versus tamoxifen versus anastrozole in the context of the German health care system, using survival data from the Breast International Group (BIG) 1-98 study and the Arimidex, Tamoxifen, Alone or in Combination (ATAC) study and generic prices. Materials and Methods: A hybrid model was developed that incorporates recurrence rates, overall survival, treatment costs and treatment-associated adverse events and the resulting costs. The basic assumption was that generic anastrozole would lead to a price reduction to $75 \%$ of the original price. Further analyses were carried out with $50 \%$ and $25 \%$ of the original prices for anastrozole and letrozole. Results: The cost-benefit model showed a gain of 0.3124 or 0.0659 quality-adjusted life years (QALYs) for letrozole or anastrozole. Incremental costs of $€ 29,375.15 /$ QALY for letrozole $(100 \%$ of original price) were calculated and $€ 94,648.03 / 0 A L Y$ for anastrozole (75\% of original price). Marked increases in cost-effectiveness are observed with further decreases in price (anastrozole: $50 \%$ price $€ 54,715.17 / \mathrm{QALY}, 25 \%$ price $€ 14,779.57 / \mathrm{QALY}$; letrozole $75 \%$ price $€ 20,988.59 / \mathrm{QALY}$, $50 \%$ price $€ 12,602.03 / \mathrm{QALY}, 25 \%$ price $€ 4,215.46 / \mathrm{QALY}$ ). Conclusion: The present model including the inverse probability of censoring weighted analysis (IPCW) for letrozole and generic prices for both Als shows that letrozole is cost effective.

\section{KARGER}

Fax +497614520714

Information@Karger.de

www.karger.com (c) 2011 S. Karger GmbH, Freiburg $1661-3791 / 11 / 0065-0381 \$ 38.00 / 0$

Accessible online at: www.karger.com/brc

\section{Schlüsselwörter}

Letrozol - Anastrozol - Tamoxifen - Kosteneffektivität . QALY $\cdot$ BIG 1-98 $\cdot$ ATAC

\section{Zusammenfassung}

Hintergrund: Aromatasehemmer (Als) sind Gegenstand von Kosteneffektivitätsanalysen, die jedoch häufig heterogen sind, bzw. Ergebnisse des krankheitsfreien Überlebens werden auf das Gesamtüberleben extrapoliert. Die vorliegende Arbeit berechnet die Kosteneffektivität von 5 Jahren Letrozol versus Tamoxifen versus Anastrozol aus der Sicht des deutschen Gesundheitswesens mit Berücksichtigung der Überlebensdaten der BIG-1-98-Studie und der ATAC-Studie und dem Patentauslaufen der Als. Material und Methoden: Im Rahmen eines Hybrid-Modells wurden neben Rezidivraten das Gesamtüberleben und die Kosten für Therapie, unerwünschte Ereignisse und Folgekosten integriert. Als Basisannahme wurde für Anastrozol ein Preisabfall auf 75\% angenommen. Folgend wurden die Analysen mit 50\% und $25 \%$ des Originalpreises von Anastrozol und Letrozol kalkuliert. Ergebnisse: Das Kosten-Nutzwert-Modell zeigt einen Zugewinn von 0,3124 bzw. 0,0659 QALYs für Letrozol bzw. Anastrozol. Es errechnen sich inkrementelle Kosten von $29375,15 € /$ QALY für Letrozol (100\% des Originalpreises) bzw. 94 648,03 €/QALY für Anastrozol (75\% des Originalpreises) im Vergleich zu Tamoxifen. Bei einem weiteren Abfall der Preise zeigt sich eine deutliche Erhöhung der Kosteneffektivität (Anastrozol: 50\%-Preis 54 715,17 €/QALY, 25\%Preis $14779,57 € / Q A L Y$; Letrozol: 75\%-Preis 20 988,59 €/ QALY, 50\%-Preis 12 602,03 €/QALY, 25\%-Preis 4215,46€/ QALY). Schlussfolgerung: Das Modell verdeutlicht unter Berücksichtigung der IPCW-Analyse (Inverse Probability of Censoring Weighted Analysis) und dem Patentauslauf für beide Als eine Kosteneffektivität für Letrozol. 


\section{Introduction}

Costs in the health care system have been increasing exponentially for years, and Germany is one of the countries with the highest costs for health care [1, 2], with drug costs having risen from $€ 19.2$ billion in 1999 to $€ 32.4$ billion in 2009 [3]. In order to meet this challenge in the longer term, an additional dimension is increasingly being incorporated into medical decision-making - the assessment of costs relative to benefit using health-economic decision-making models. In Germany, following the latest health care reform (the Drug Market Reform Law, Arzneimittelmarktneuordnungsgesetz, AMNOG), a rapid evaluation of the benefit of drugs is carried out by the Joint Federal Committee (Gemeinsamer Bundesausschuss, GBA) with support from the Institute for Quality and Economic Efficiency in the Health Care System (Institut für Qualität und Wirtschaftlichkeit im Gesundheitswesen, IQWiG) [4]. A review of published analyses shows that the qualityadjusted life-year (QALY, i.e. an additionally gained year of life with $100 \%$ quality of life due to a measure taken) and the incremental cost-effectiveness ratio (ICER, i.e. the costs required to gain $1 \mathrm{QALY}$ through a new form of treatment in comparison with the standard procedure) are continuing to be accepted internationally.

Endocrine therapies in the adjuvant setting for patients with hormone receptor-positive breast carcinoma are an important part of health economics studies. The 5-year prevalence for all women with breast carcinoma over the age of 50 (usually postmenopausal women) is 193,000 in Germany [5]. Assuming that $71.5 \%$ of these carcinomas are hormone receptor positive [6], treatment with an aromatase inhibitor (AI) may potentially affect 137,995 women. It is understandable that the benefits of endocrine therapy in comparison with its risks and costs need to be weighed up from the point of view of the health care system.

A 5-year course of treatment with tamoxifen has led to a reduction in the relative risk of recurrence by $50 \%$ and an increase in survival by $25 \%$ in these patients. However, up to $50 \%$ of the women can potentially develop more advanced disease (progression) [7]. In addition, tamoxifen is associated with sometimes severe side effects, such as endometrial carcinoma or thromboses and embolism. By contrast, AIs are more effective than tamoxifen in both metastatic and adjuvant situations [8-11]. Administration of AIs leads to higher direct drug costs, but these agents are also more effective by preventing recurrences and metastases, which may be associated with much higher subsequent costs. Cost-effectiveness analyses can make an important contribution here.

Due to numerous differences between the health care systems, an analysis specific of the health care system in Germany, taking the costs that arise here into account, is necessary. In addition, many cost-effectiveness studies have mingled the results for disease-free survival and overall survival, or have extrapolated the results for disease-free survival to overall survival, and this has given rise to critical debate. A cost-effectiveness analysis focusing on efficacy relative to overall survival thus appears to be necessary. Furthermore, in 2011, anastrozole was the first AI to become a generic agent, and this will lead to a reduction in the price of the drug.

The present study addresses these aspects and estimates the cost-effectiveness of 5 years of treatment with letrozole and 5 years of anastrozole, each in comparison with 5 years of tamoxifen, in the context of the German health care system and based on the survival data from the Breast International Group (BIG) 1-98 study and the Arimidex, Tamoxifen, Alone or in Combination (ATAC) study, taking into account the current expiry of the patent for anastrozole and the impending expiry of the patent for letrozole.

\section{Material and Methods}

\section{Model}

A hybrid model was developed to estimate the cost-benefit ratio of endocrine treatments in adjuvant therapy. The model on the one hand includes recurrence rates and also overall survival with the individual forms of treatment, and on the other hand combines these with a Markov model for the costs of treatment and treatment-associated adverse events and their resulting costs [12]. All of the patients included in the model were postmenopausal and had a hormone receptor-positive breast carcinoma. The results were calculated as costs per QALY. A time period of 20 years was used in order to record the long-term effects of treatment. The discounting rate was $3 \%$, in accordance with the IQWiG recommendations [13].

\section{Efficacy Data}

Both locoregional recurrences and distant metastases were defined as disease-specific events. Mortality tables for calculating survival probabilities for the first 7 years were based on the tamoxifen arm of the BIG 1-98 study $[8,9]$. Data for cohorts of patients in the Early Breast Cancer Trialists' Group (EBCTG) study who had taken tamoxifen for 5 years were used for survival data for years 8-10 [7]. Survival in years 11-15 was estimated using the annual mortality ratio for years 1-10 in the EBCTG study cohorts. The data from the EBCTG study were chosen here as they are based on larger numbers of patients with a longer follow-up period. For the subsequent years (16-20), general mortality tables for the general population for women aged 76-80 years were used.

Hazard ratios (HRs) for letrozole versus tamoxifen and for anastrozole versus tamoxifen from the studies mentioned above were used to calculate overall survival following treatment with letrozole and anastrozole. The comparison of letrozole versus tamoxifen is based on the HR for the first 7 years, corresponding to the published follow-up from the BIG 1-98 study [9]. The data from the BIG study are based on the inverse probability of censoring weighted analysis (IPCW) [10]. The data for anastrozole versus tamoxifen are based on the published 9-year follow-up data from the ATAC study [11].

It was assumed that the subsequent annual survival probabilities in the 3 groups were identical, as no further data were available here. However, the mortality with the 2 AIs is higher, as more individuals in these groups are alive at the end of the follow-up period than in the group with tamoxifen treatment.

Cost Data

All costs are based on data from the German health care system for the year 2010. The costs of care, diagnosis and treatment were estimated for 
outpatients on the basis of the 2010 Standard Assessment Criteria (Einheitlicher Bewertungsmassstab, EBM) (EBM score 3.5048 cents) [14], and for inpatients on the basis of the 2010 diagnosis-related group (DRG) case rate catalog used in the Diagnosis-Related Groups in Germany (G-DRG) system. It was assumed that follow-up care was provided for each diagnosis in accordance with the current S3 guideline [15]. It was also assumed in the calculations that all patients receiving an AI annually underwent a dual-energy X-ray absorptiometry (DXA) scan to check for bone density during therapy, and that all patients receiving tamoxifen therapy underwent a vaginal ultrasound examination every 6 months to check the endometrial thickness.

Drug costs were recorded in accordance with the standard sources [16]. A price of $75 \%$ of the current costs was assumed as a basic model for generic anastrozole, in accordance with the question addressed in the model. Cost-effectiveness was then also calculated for $50 \%$ and $25 \%$ of the original price of anastrozole, as well as for $75 \%, 50 \%$ and $25 \%$ of the original price of letrozole.

The incidences of adverse and severe adverse events were taken from the BIG 1-98 and ATAC studies. The costs of treatment for these events were calculated using published data or standard care as set by an expert panel. In the model, adverse side effects only occurred during treatment.

The costs of diagnosis and consequent treatment for a disease-specific event were calculated in the same way as the costs for adverse events.

\section{Quality of Life Data}

Morbidity, mortality and quality of life were included in this cost-effectiveness analysis in combined form through QALYs. To calculate QALYs, data on health utilities in the various treatment and disease settings were required. As international data may diverge considerably from those in women living in Germany, health utilities were obtained at the Department of Gynecology in the Erlangen University Hospital using a visual analog scale (VAS; scale $0-100)$. Health utilities were obtained and evaluated for 600 patients so that the present analysis was able to draw on real data for women treated in Germany [17]. Table 1 shows the health utilities for the various disease situations.

When data for changes in health utilities were lacking relative to adverse and severe adverse events that occurred, with the exception of primary disease in endometrial carcinoma, published values from American and British breast carcinoma patients were used [18]. The mean age was 68 years. All patients received an endocrine therapy in the adjuvant setting. $56 \%$ had a previous radiotherapy and $16 \%$ adjuvant chemotherapy. Health status due to adverse events associated with endocrine therapy was assessed using the standard gamble technique for 67 patients (table 2). Here, the patients had to choose between 2 alternatives: gamble of living in perfect health versus immediate death, or certainty of being in the hypothetical health state being measured. Then scores were adjusted to a scale of $0-1.0$.

\section{Sensitivity Analysis}

Sensitivity analyses were carried out to test the uncertainty of the data entered into the model. Simple standard deviation was used for cost parameters, and published confidence intervals were used for clinical efficacy parameters. Probability calculation was carried out using a Monte Carlo simulation with 2000 scenarios. The validity of the model is presented using cost effectiveness-acceptance curves, which present the probabilities of the various incremental cost-effectiveness ratios (ICERs).

\section{Results}

\section{Parameters in the Model}

The costs calculated for the endocrine treatments and for patient care, taking into account the assumed price reductions ( $75 \%, 50 \%$ and $25 \%$ ), are shown in table 3 .

Table 1. Health utilities in the model relative to the disease situation [17]

\begin{tabular}{lllll}
\hline Disease situation & $\begin{array}{l}\text { Data collection } \\
\text { method }\end{array}$ & $\mathrm{n}$ & Median & Standard deviation \\
\hline Disease free during follow-up with status post breast carcinoma & VAS & 168 & 75.000 & 17.3169 \\
Recurrent breast carcinoma & VAS & 19 & 71.500 & 18.5663 \\
Metastatic breast carcinoma, overall & VAS & 84 & 70.000 & 20.8940 \\
Recurrent and metastatic breast carcinoma & VAS & 29 & 69.000 & 22.0691 \\
Metastatic breast carcinoma, chemotherapy & VAS & 25 & 58.000 & 23.3128 \\
Metastatic breast carcinoma, endocrine therapy & VAS & 27 & 70.000 & 19.0694 \\
Primary disease endometrial carcinoma & VAS & 11 & 60.000 & 13.6518 \\
\hline
\end{tabular}
VAS = Visual analog scale.

Table 2. Health utilities in the model relative to adverse events [18]

Table 3. Drug costs and treatment costs for the model (based on pharmacists' prices in 2010 (100 tablets N3)

\begin{tabular}{llll}
\hline Event & $\mathrm{n}$ & Mean & Standard deviation \\
\hline No event & 67 & 0.974 & 0.033 \\
Weight gain, hot flushes, vaginal discharge & 67 & 0.963 & 0.042 \\
Weight gain, limb pain, hot flushes, dryness of vagina & 67 & 0.959 & 0.050 \\
Deep venous thrombosis in legs & 67 & 0.796 & 0.250 \\
Hip fracture & 67 & 0.730 & 0.290 \\
\hline
\end{tabular}

\begin{tabular}{lllcr}
\hline Drug & $\begin{array}{l}\text { Costs for care, including prescriptions, } \\
\text { per 3 months, } €\end{array}$ & $\begin{array}{l}\text { Price reductions assumed } \\
\text { in the model, \% }\end{array}$ & $\begin{array}{l}\text { Drug costs } \\
\text { per 3 months, } €\end{array}$ & $\begin{array}{l}\text { Costs } \\
\text { per year, } €\end{array}$ \\
\hline Tamoxifen & 50.83 & 100 & 20.46 & 285.16 \\
Anastrozole & 38.87 & 100 & 606.77 & 2582.56 \\
& & 75 & 455.08 & 1975.80 \\
& & 50 & 303.39 & 1369.04 \\
Letrozole & \multirow{2}{*}{38.87} & 25 & 151.69 & 762.24 \\
& & 100 & 603.96 & 2571.32 \\
& & 50 & 452.97 & 1967.36 \\
& 25 & 301.98 & 1363.40 \\
\end{tabular}




\begin{tabular}{|c|c|c|c|}
\hline Cost type & Period & Costs per year, $€$ & Reference \\
\hline \multirow{3}{*}{ No events (follow-up care without any findings) } & years $1-3$ & 360.92 & \multirow{2}{*}[19]{} \\
\hline & years 4 and 5 & 227.40 & \\
\hline & year 1 & $15,044.01$ & \multirow{4}{*}[19,20]{} \\
\hline \multirow{3}{*}{ Recurrences } & years 2 and 3 & 574.79 & \\
\hline & years 4 and 5 & 441.27 & \\
\hline & year 1 & $18,361.62$ & \\
\hline \multirow[t]{2}{*}{ Contralateral breast carcinoma } & years 2 and 3 & 574.79 & \multirow[t]{2}{*}[19]{} \\
\hline & years 4 and 5 & 441.27 & \\
\hline Metastases & year 1 & $19,514.27$ & {$[21]$} \\
\hline Terminal care & last 4 weeks & 7472.39 & [19] \\
\hline
\end{tabular}

Table 4. Costs for follow-up care and disease-specific events

\begin{tabular}{|c|c|c|c|}
\hline Adverse/severe adverse event & Period & Costs, $€$ & Reference \\
\hline Transitory ischemic attack (TIA) & first 3 months from event & 3078.48 & {$[16,22]$} \\
\hline Thromboembolism & first 3 months from event & 2463.39 & {$[16,23]$} \\
\hline Vaginal bleeding & per event & 1319.72 & {$[14,23]$} \\
\hline Arthralgia & per month & 27.04 & {$[14,16]$} \\
\hline Myalgia & per month & 27.04 & {$[14,16]$} \\
\hline \multirow[t]{4}{*}{ Endometrial carcinoma } & per event & 6879.52 & {$[14,23]$} \\
\hline & follow-up care, per visit & 89.94 & \\
\hline & overall follow-up care & 1439.04 & \\
\hline & overall costs & 8318.56 & \\
\hline Bone fracture, without surgery & per event & 2074.22 & {$[16,23]$} \\
\hline Bone fracture, with surgery (with femoral fracture as example) & per event & 5340.79 & {$[14,16]$} \\
\hline
\end{tabular}

Table 5. Costs of adverse and severe adverse events
In addition to direct costs for drugs, these also include the costs for diagnosis (e.g., physical examination, DXA scanning) and care (patient history, physical examination, prescriptions, etc.). The different costs for care are based on the vaginal ultrasound and examination every 6 months in case of tamoxifen.

The costs calculated for follow-up measures and for the occurrence of disease-specific events (recurrences, contralateral breast carcinoma, metastases) are shown in table 4 [19-21], and the costs calculated for adverse events and severe adverse events for each type of endocrine therapy are shown in table $5[14,16,22,23]$.

\section{Cost-Benefit Analysis}

Using the present analysis, total costs for the basic assumption ( $75 \%$ price for anastrozole and $100 \%$ price for letrozole) of $€ 16,308.10$ for adjuvant endocrine therapy with tamoxifen, $€ 25,484.12$ for letrozole, and $€ 22,546.14$ for anastrozole were calculated (table 6). The substantial differences from tamoxifen are due in particular to differences in direct treatment costs of $€ 9934.58$ for letrozole and $€ 7351.45$ for anastrozole, and the difference here is explained by the expiry of the patent for anastrozole, with an assumed price for the generic drug equivalent to $75 \%$ of the original price. With regard to efficacy, gains of 0.3090 life-years for letrozole and 0.0440 life-years for anastrozole were calculated in comparison with tamoxifen. With regard to costs, incremental costs of $29,691.85$ per life-year for letrozole ( $100 \%$ price) in comparison with tamoxifen and $€ 141,673.73$ per life-year for anastrozole ( $75 \%$ price) in comparison with tamoxifen were calculated (table 6). In addition, the cost-benefit model based on survival, taking into account the health utilities obtained in
Germany, shows gains of 0.3124 and 0.0659 QALYs for letrozole and anastrozole, respectively, in comparison with 5 years of treatment with tamoxifen.

With regard to costs, incremental costs of $€ 29,375.15$ per QALY (95\% confidence interval (CI), € 17,323-122,339) for letrozole $(100 \%$ price) in comparison with tamoxifen and $€ 94,648.03$ per QALY $(95 \%$ CI, $€ 25,997-1,010,381)$ for anastrozole ( $75 \%$ price) in comparison with tamoxifen were calculated (table 6).

The cost-effectiveness improves markedly with a further reduction in the price of anastrozole; at $50 \%$ of the original price, the figure would be $€ 54,715.17$ per QALY, and at $25 \%$ of the price, it would be $€ 14,779.67$ per QALY.

By contrast, the cost-effectiveness after a price reduction with letrozole continues to favor letrozole. With a price reduction after expiry of the patent to $75 \%$ of the original price, the cost-effectiveness would be $€ 20,988.59$ per QALY; at $50 \%$, it would be $€ 12,602.03$ per QALY, and at $25 \%$ of the price it would be $€ 4215.46$ per QALY (table 6).

\section{Sensitivity Analysis}

The probability of cost-effectiveness with the basic assumption for letrozole $(100 \%)$ versus anastrozole $(75 \%)$ is illustrated in figure 1 . The resulting probability curves for costeffectiveness in comparison with tamoxifen for the various prices are shown in figures 2 and 3.

Moreover, the scatter plot of the basic assumption scenario ( $75 \%$ price for anastrozole and $100 \%$ price for letrozole) is presented in figure 4 . This cost-effectiveness plane represents the cost and QALY differences for each of the separate runs that are undertaken as part of the probabilistic sensitivity analysis. The chart shows that letrozole is always more costly, 


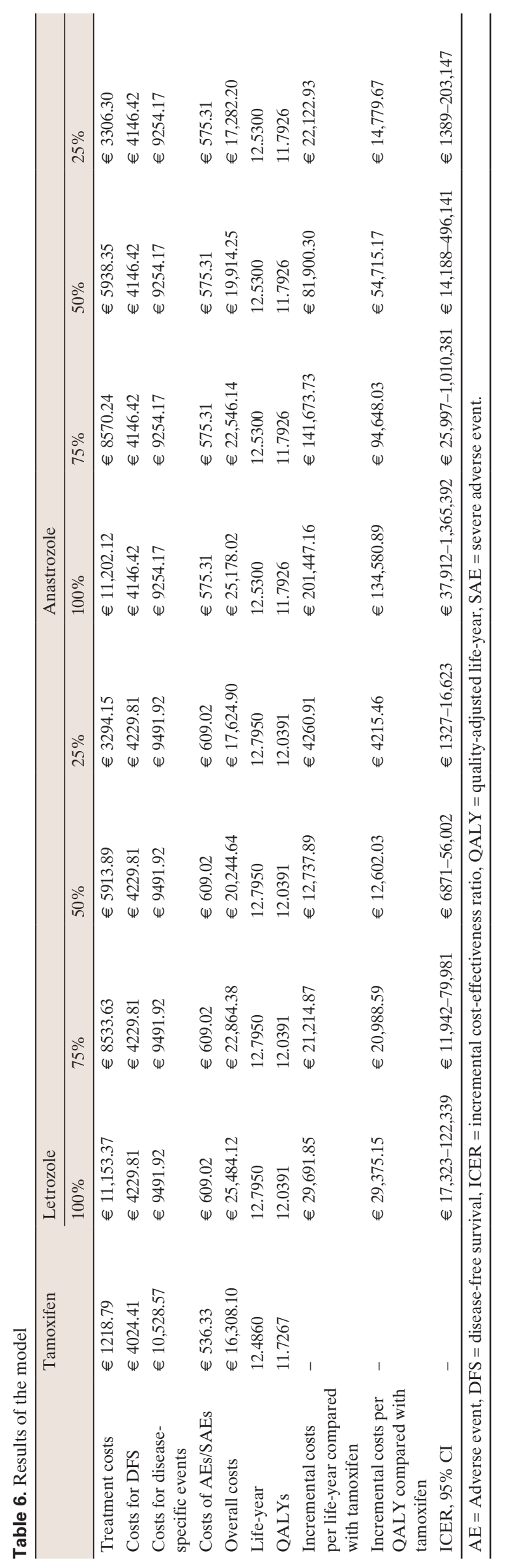

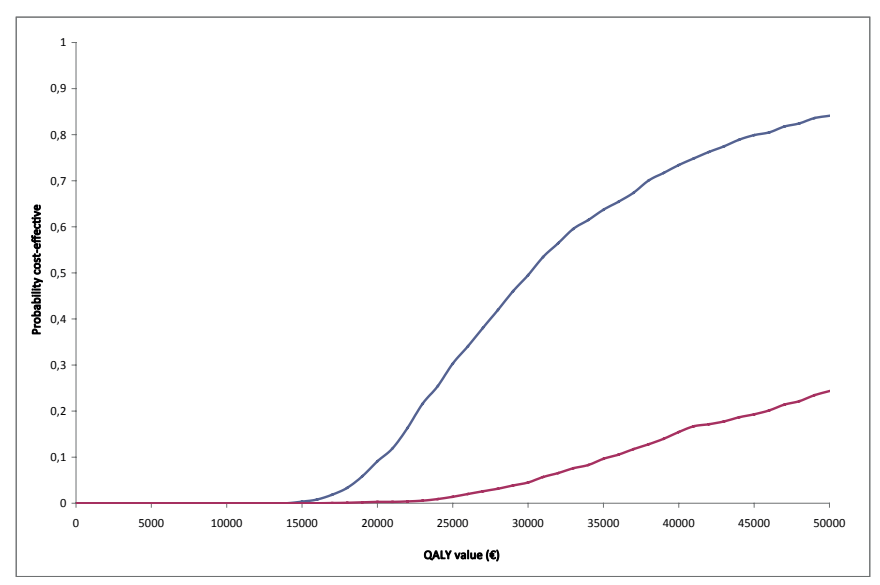

Fig. 1. Cost-effectiveness curve for the initial model for anastrozole (red) at $75 \%$ of the original price versus letrozole (blue) at $100 \%$ of the original price.

but it is also always more effective than tamoxifen, whereas anastrozole has a fair probability of being less effective than tamoxifen.

\section{Discussion}

Numerous studies have been published in recent years on the use of AIs in the adjuvant setting, but none of these has taken the potential generic prices for the agents into account. A total of 20 publications were evaluated in a recent metaanalysis ( 8 on anastrozole, 8 on letrozole, and 4 on exemestane) [24]. Median ICERs of $\$ 21,113$ for letrozole, $\$ 21,428$ for exemestane, and $\$ 24,932$ for anastrozole were found. As all of the values were below the accepted threshold value of $\$ 25,000$, the authors concluded that administration of AIs is always a cost-effective option in comparison with tamoxifen.

Another published meta-analysis of the available economic analyses of the 3 AIs in comparison with tamoxifen was carried out by the Health Technology Assessment (HTA) program in 2007 to provide data for decisions taken by the National Institute for Health and Clinical Excellence (NICE) [25]. The AIs were evaluated as a cost-effective form of treatment. However, it was emphasized, qualifying this, that further research results are needed to confirm the usual extrapolation of the benefits in terms of disease-free survival and recurrence-free survival to the overall survival as well. These data are now available.

In the 100-month data for the ATAC study, a significantly longer disease-free survival (HR 0.85; 95\% CI 0.76-0.94; $\mathrm{p}=0.003)$ and a significantly longer period to recurrence (HR 0.76 ; 95\% CI 0.67-0.87; $\mathrm{p}=0.0001$ ) was observed for anastrozole in comparison with tamoxifen [11]. Although fewer deaths occurred in the anastrozole arm (472 versus 477), the overall survival was not significantly longer (HR 0.97; 95\% CI 0.86-1.11; $\mathrm{p}=0.7)$. In the BIG 1-98 study, an 

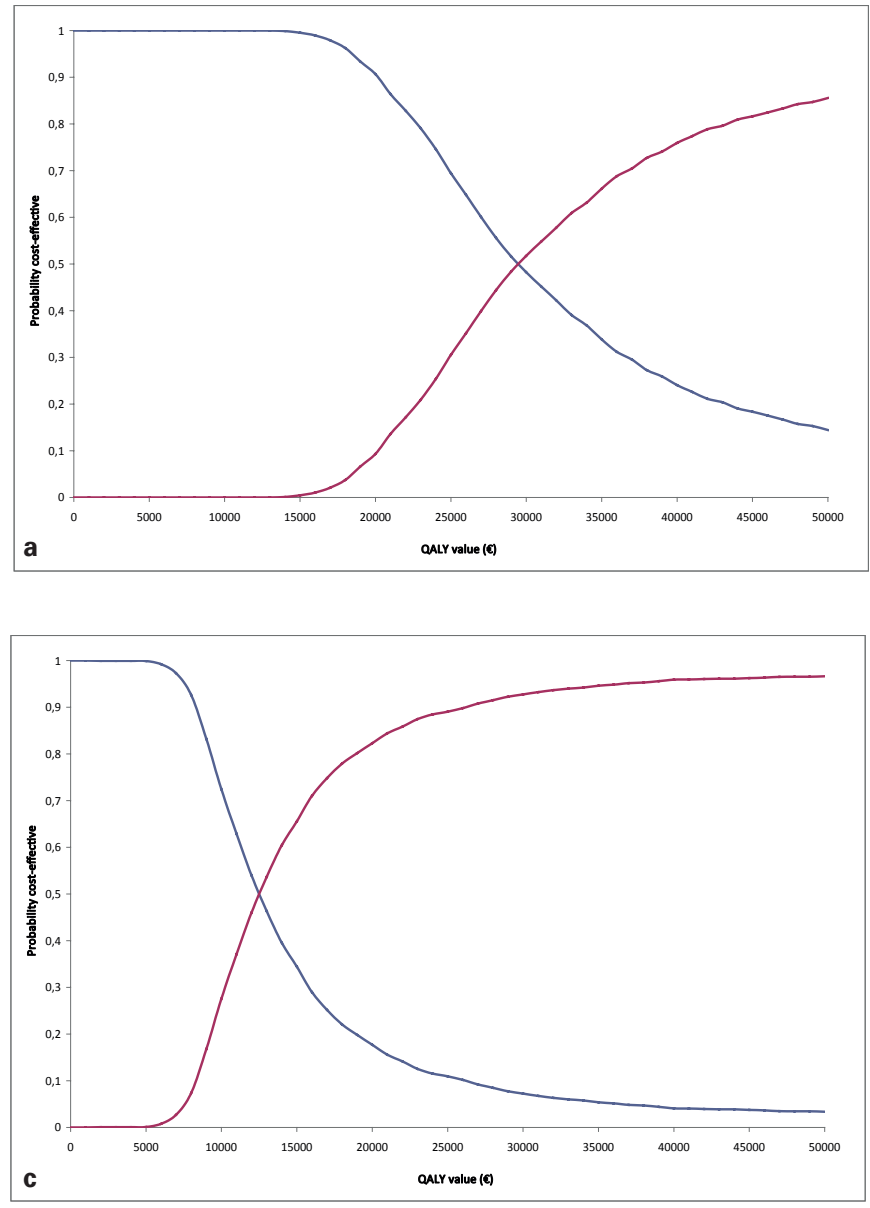

Fig. 2. Cost-effectiveness curve for letrozole (red) at (a) $100 \%$, (b) $75 \%$,
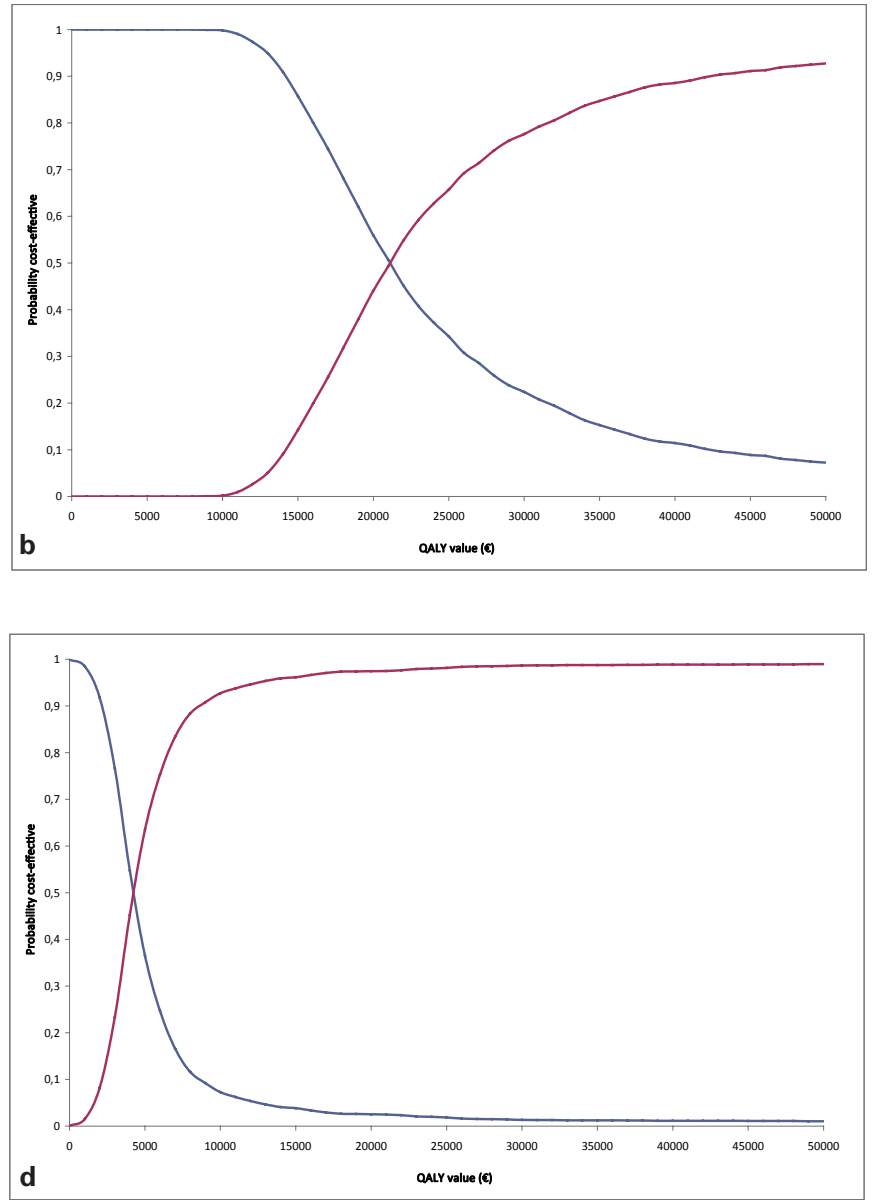

(c) $50 \%$, and (d) $25 \%$ of the original price versus tamoxifen (blue).

intention-to-treat (ITT) analysis of the 2 single-treatment arms (5 years of letrozole versus 5 years of tamoxifen) after a median follow-up period of 76 months showed a significant advantage for letrozole, both in relation to recurrence-free survival (HR 0.88; 95\% CI 0.79-0.99) and also distant metastasis-free survival (HR 0.85; 95\% CI 0.7-1.00). With regard to the overall survival, the ITT analysis showed a trend in favor of the AI (HR 0.87; 95\% CI 0.7-1.02) [9]. The problem with these data is that, due to the better effectiveness that was emerging for letrozole, unblinding of the study was carried out for ethical reasons, as a result of which $25 \%$ of the women switched to the letrozole arm. This selective cross-over made subsequent analysis more difficult, as these women continued to be assigned to the control arm in the ITT analysis, reducing the potential difference between the 2 treatment arms. This led to a censored analysis, in which a significant difference was found in the overall survival (HR 0.81; 95\% CI 0.69-0.94) (fig. 4) [10]. To compensate for underestimation in the ITT analysis and overestimation in the censored analysis, an IPCW analysis of the BIG 1-98 study was published [10], which provides an opportunity to see how the study might have fared without selective cross-over. It was shown once again that letrozole significantly improved the overall survival by $17 \%$ in comparison with tamoxifen (HR 0.83; 95\% CI 071$0.97 ; \mathrm{p}<0.05)$ [10]. As expected, the results were intermediate between the figures for the ITT and censored analyses.

The present cost-benefit analysis incorporates the survival data mentioned above; taking into account expected price reductions due to the expiry of the patent for anastrozole to $75 \%, 50 \%$ and $25 \%$ of the original price and the future expiry of the patent for letrozole, with the same estimated price reductions, the study compares the cost-benefit values for letrozole and anastrozole with tamoxifen in postmenopausal patients with hormone-receptive breast carcinoma. For the basic assumption with letrozole (100\% of the price), the costbenefit figure is $€ 29,375.15$ per QALY. This is also the first cost-benefit analysis for letrozole in comparison with tamoxifen in the context of the German health care system that takes health utilities in Germany into account.

Comparable international data are available [26, 27]. Delea et al. [26] investigated the cost-benefit ratio for letrozole in comparison with tamoxifen on the basis of the American health care system and data from the BIG 1-98 study, assuming a carry-over effect of 5 years. A gain of 0.409 QALYs in 

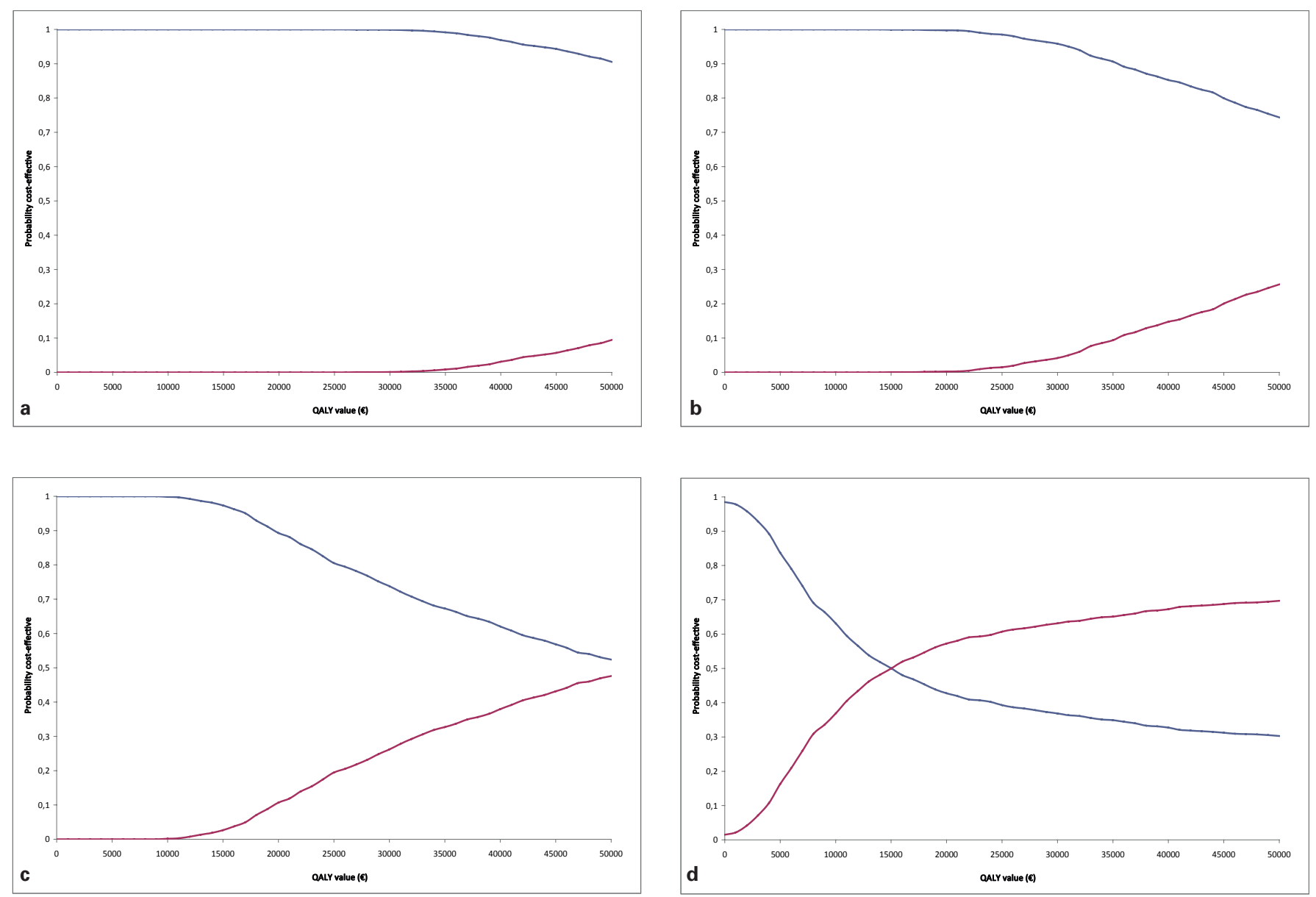

Fig. 3. Cost-effectiveness curve for anastrozole (red) at (a) $100 \%$, (b) $75 \%$, (c) $50 \%$, and (d) $25 \%$ of the original price versus tamoxifen (blue).

comparison with tamoxifen and additional costs of \$9705 with letrozole treatment were observed. This led to costs of \$23,743 per QALY (95\% CI, \$14,087-51,129).

Numerous published cost-benefit analyses are also available for anastrozole in comparison with tamoxifen, although most of these are based on the 60-month data from the ATAC study [28-33]. Karnon [32] previously carried out a meta-analysis of the published data for the AIs, showing that anastrozole is cost effective. An analysis from the point of view of the American health care system estimated an ICER of \$20,246 per QALY for anastrozole in comparison with tamoxifen [31].

By contrast, the present analysis shows a cost-benefit value of $€ 94,648.03$ (95\% CI, $€ 25,997-1,010,381)$ for up-front therapy with anastrozole at $75 \%$ of the original price in comparison with treatment with tamoxifen. At $100 \%$ of the original price, the figure would be as high as $€ 134,580.89$ per QALY (table 6). This result clearly diverges from the previously published data, including those reported in a study based on the health care system in Germany [34]. Using the ATAC 100-month data, the latter study indicated costs of $€ 21,069$ per QALY gained (95\% CI, $€ 12,567-46,604)$. The

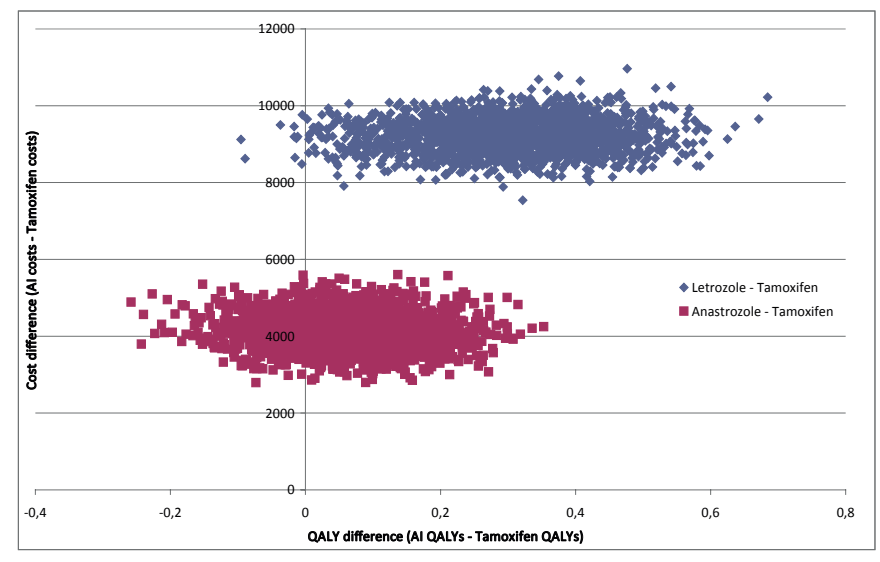

Fig. 4. Scatter plot of the basic assumption scenario (75\% price for anastrozole and $100 \%$ price for letrozole - cost and QALY differences).

differences are based on the problem that the ATAC study did not show a significant benefit in relation to overall survival, but only for disease-free survival. However, numerous cost-benefit analyses for AIs have extrapolated the disease- 
free survival to the overall survival. This procedure is a matter of controversy [35, 36]. But Cuzick argues in his paper that disease-free survival is a widely accepted end point in numerous clinical studies [35], so that overall survival in a group with an initially good prognosis cannot be used, as the patients die due to other diseases and the overall survival resulting from a therapeutic innovation is no longer measurable. In the publication by Lux et al. [34] mentioned above, a longer overall survival was estimated on the basis of a significantly prolonged time to recurrence due to treatment with anastrozole. Although this assumption is accepted from the health economics point of view, it was dispensed with in the present analysis, and the pure published survival data from the studies were used without extrapolation in order to avoid additional uncertainties in the model.

A comparable analysis using IPCW data from the BIG 1-98 study in comparison with data from the ATAC study has also been published [37]. Over a period of 20 years, the discounted additional treatment costs for letrozole were $\leq £ 3618$. Taking all adverse side effects and avoidance of recurrences into account, the cost difference from tamoxifen was $\leq £ 2964$. With a gain of 0.297 QALYs, an ICER of $\leq £ 9999$ for letrozole was estimated. For anastrozole, this value was $\leq £ 48,829$. The authors concluded that letrozole is a substantially better strategy in comparison with anastrozole. These data from England confirm both the present results from the German study and also the validity of the model based on survival data.

Although the results of this work are confirmed by several international studies, some limitations have to be mentioned. The results are based on a model. The validation with real data would be helpful and should be part of health services research. Moreover, the model is based on the IPCW analysis, which can only weight known patient characteristics and tumor parameters. An adjustment of unknown prognostic factors is not possible.

One further statistical limitation is the fact that the mortality tables for the 76-80-year-old women are based on the general population. A bias is possible, because mortality rates 15-20 years post early breast cancer will be low compared to all-cause mortality rates. This may slightly underestimate mortality. Increasing the mortality probabilities in this age group to $5 \%$ increases the ICER of letrozole by $€ 200$; so the effect on the cost-effectiveness would be marginal.
Last but not least, compliance has to be mentioned, which could influence the results of the model. It is known that compliance in real life is different to clinical trials. This is especially relevant for endocrine therapies regarding the long duration of intake (at least 5 years, up to 10 years possible) und the side effects. Non-adherence and non-persistence due to non-compliance can decrease overall survival $(\mathrm{HR}=1.26$ and HR = 1.49) [38]. Moreover, it can cause costs by additional relapses and metastasis, which need cost-intensive therapies. On the other side, results of cost-effectiveness models can have a positive influence on the perception of endocrine therapies and optimize compliance.

\section{Conclusions}

The present model - taking into account the current state of data with an IPCW analysis for letrozole and also the current expiry of the patent for anastrozole and the impending expiry of the patent for letrozole - shows that letrozole is cost effective in postmenopausal patients with hormone receptor-positive breast carcinoma. The new Drug Market Reform Law of November 2010 introduced rapid evaluation of new drugs to demonstrate additional benefit in Germany. Although the German model was based on the Scottish Medicines Consortium (SCM) method of assessing new drugs, there are clear differences. Whereas a cost-benefit assessment is carried out in Scotland and a threshold value of $€ 30,000 /$ QALY is set for a positive judgement of benefit, in Germany only the benefit is assessed, without a threshold value. However, the present analysis does also meet the criteria for cost-effectiveness using the Scottish threshold value.

It is also the first cost-benefit analysis for letrozole in comparison with tamoxifen to be conducted in the context of the German health care system, taking into account health utilities in Germany, potential price reductions for both drugs, and current survival data.

\section{Disclosure Statement}

The presented model was designed with financial support from Novartis Oncology (statistical analysis, travel costs and expenses, translation). The expert panel for the model consisted of independent clinical physicians. 


\section{References}

1 Porzsolt F: Klinische Ökonomik. Die ökonomische Bewertung von Gesundheitsleistungen aus der Sicht des Patienten; in Porzsolt F, Williams AR, Kaplan RM (eds): Klinische Ökonomik. Effektivität und Effizienz von Gesundheitsleistungen. Landsberg, ecomed, 2003, pp 17-40.

2 Lux MP, Beckmann MW: Klinische Ökonomie in der gynäkologischen Onkologie. Frauenheilkd Akt 2008;2:35-41.

3 Bundesministerium für Gesundheit: www.bmg.bund.de/ krankenversicherung/arzneimittelversorgung/amnog. html, 2011.

4 Bundesministerium für Gesundheit: Gesetz zur Neuordnung des Arzneimittelmarktes (AMNOG). www.bmg.bund.de/krankenversicherung/ arzneimittelversorgung/amnog/amnog.html, 2010.

5 Robert Koch-Institut: Verbreitung von Krebserkrankungen in Deutschland. Entwicklung der Prävalenzen zwischen 1990 und 2010. Beiträge zur Gesundheitsberichterstattung des Bundes. Berlin, Westkreuz-Druckerei, 2010, pp 77-82.

6 Brown SB, Mallon EA, Edwards J, Campbell FM, McGlynn LM, Elsberger B, Cooke TG: Is the biology of breast cancer changing? A study of hormone receptor status 1984-1986 and 1996-1997. Br J Cancer 2009;100:807-810.

7 [No authors listed]: Tamoxifen for early breast cancer: an overview of the randomised trials. Early Breast Cancer Trialists' Collaborative Group. Lancet 1998;351:1451-1467.

8 Thürlimann B, Keshaviah A, Coates AS, Mouridsen H, Mauriac L, Forbes JF, Paridaens R, Castiglione-Gertsch M, Gelber RD, Rabaglio M, Smith I, Wardley A, Price KN, Goldhirsch A; Breast International Group (BIG) 1-98 Collaborative Group: A comparison of letrozole and tamoxifen in postmenopausal women with early breast cancer. N Engl J Med 2005;353:2747-2757.

$\checkmark 9$ Mouridsen HT, Giobbie-Hurder A, Mauriac L, Paridaens R, Colleoni M, Thuerlimann B, Forbes JF Gelber RD, Wardley A, Goldhirsch A; BIG 1-98 Collaborative Group and International Breast Cancer Study Group (IBCSG), Bern, Switzerland: BIG 1-98: a randomized double-blind phase III study evaluating letrozole and tamoxifen given in sequence as adjuvant endocrine therapy for postmenopausal women with receptor-positive breast cancer. Cancer Res 2009;69(suppl):abstr 13.

10 Regan MM, Colleoni M, Giobbie-Hurder A, Thuerlimann B, Mouridsen H, Mauriac L, Paridaens R, Forbes JF, Wardley A, Smith I, Price KN, Goldhirsch A, Coates AS, Gelber RD BIG 1-98 Collaborative and International Breast Cancer Study groups. Adjusting for selective crossover in analyses of letrozole (Let) versus tamoxifen (Tam) in the BIG 1-98 Trial. Cancer Res 2009;69(suppl):488s-489s.

11 Arimidex, Tamoxifen, Alone or in Combination (ATAC) Trialists' Group, Forbes JF, Cuzick J, Buzdar A, Howell A, Tobias JS, Baum M: Effect of anastrozole and tamoxifen as adjuvant treatment for early-stage breast cancer: 100-month analysis of the ATAC trial. Lancet Oncol 2008;9:45-53.

12 Sonnenberg FA, Beck JR: Markov models in medical decision making: a practical guide. Med Decis Making 1993;13:322-338.

13 Institut für Qualität und Wissenschaftlichkeit im Gesundheitswesen: Methods for assessment of the relation of benefits to costs in the German statutory health care system. Version 1.1. http://iqwig.de/ index.805.en.html, 2008.
14 Kassenärztliche Vereinigung Bayerns: Bayerische Euro-Gebührenordnung und EBM-Änderungen ab 1. April 2010. www.kvb.de, 2010.

15 Deutsche Krebsgesellschaft; Kreienberg R, Kopp I, Albert U, Bartsch HH, Beckmann MW, Berg D, Bick U, du Bois A, Budach W, Dunst J, Engel J, Ernst B, Geraedts M, Henscher U, Hölzel D, Jackisch C, König K, Kreipe H, Kühn T, Lebeau A, Leinung S, Link $\mathrm{H}$, Lück $\mathrm{HJ}$, Madjar H, Maiwald A, Maiwald G, Marschner N, Marx M, von Minckwitz G, Nass-Griegoleit I, Possinger K, Reiter A, Sauerbrei W, Schlake W, Schmutzler R, Schreer I, Schulte H, Schulz KD, Souchon R, Thomssen C, Untch M, Wagner U, Weis J, Zemmler T: Interdisziplinäre S3-Leitlinie - Diagnostik, Therapie und Nachsorge beim Mammakarzinom. Munich, Zuckschwerdt Verlag, 2008.

16 Rote Liste: Rote Liste ${ }^{\circledast}$ Service GmbH 2010. www. rote-liste.de,info@rote-liste.de.

17 Lux MP, Graf C, Hildebrandt T, Bani MR, Löhberg CR, Schrauder MG, Thiel FC, Fasching PA, Beckmann MW: Health Utilities in der Gynäkologischen Onkologie und Senologie in Deutschland. Onkologie 2010;33(suppl 2):191.

18 Sorensen S, Brown R, Benedict A: Patient-rated utilities in postmenopausal early breast cancer: a cross country comparison. Value Health 2004;7: 637-657.

19 Lux MP, Reichelt C, Wallwiener D, Kreienberg R, Jonat W, Gnant M, Beckmann MW, Thiel FC: Results of the Zometa cost-utility model for the German healthcare system based on the results of the ABCSG-12 study. Onkologie 2010;33:360-368.

20 Wagner S, Bani MR, Fasching PA, Schrauder MG, Löhberg CR, Beckmann MW, Lux MP: Ist ein Brustzentrum finanzierbar? - Berechnung einzelner Leistungen am Beispiel des Universitäts-Brustzentrums Franken (UBF). Geburtshilfe Frauenheilkd 2008:68:1178-1183.

21 Lux MP, Hartmann M, Jackisch C, Raab G, Schneeweiss A, Possinger K, Oyee J, Harbeck N: Cost-utility analysis for advanced breast cancer therapy in Germany: results of the fulvestrant sequencing model. Breast Cancer Res Treat 2009; 117:305-317

22 Dodel RC, Haacke C, Zamzow K, Paweilik S, Spottke A, Rethfeldt M, Siebert U, Oertel WH, Schöffski O, Back T: Resource utilization and costs of stroke unit care in Germany. Value Health 2004; 7:144-152.

23 3M Suite. http://solutions.3mdeutschland.de/wps/ portal/3M/de_DE/his/drg/product-information/ coding-grouping/3msuite, 2010.

24 Topaloglu O, Unalp A: Review of cost-effectiveness studies on aromatase inhibitors for the treatment of early-stage breast cancer. J Clin Oncol 2010;28(suppl 15):abstr e11030.

25 Hind D, Ward S, De Nigris E, Simpson E, Carroll C, Wyld L: Hormonal therapies for early breast cancer: a systematic review and economic evaluation. Health Technol Assess 2007;11:iii-iv, ix-xi, $1-134$.

26 Delea TE, Karnon J, Sofrygin O, Thomas SK, Papo NL, Barghout V: Cost-effectiveness of letrozole versus tamoxifen as initial adjuvant therapy in hormone receptor-positive postmenopausal women with early-stage breast cancer. Clin Breast Cancer 2007;7:608-618.
27 Delea TE, El-Ouagari K, Karnon J, Sofrygin O Cost-effectiveness of letrozole versus tamoxifen as initial adjuvant therapy in postmenopausal women with hormone-receptor positive early breast cancer from a Canadian perspective. Breast Cancer Res Treat 2008;108:375-387.

28 Mansel R, Locker G, Fallowfield L, Benedict A, Jones D: Cost-effectiveness analysis of anastrozole vs tamoxifen in adjuvant therapy for early stage breast cancer in the United Kingdom: the 5-year completed treatment analysis of the ATAC ('Arimidex', Tamoxifen Alone or in Combination) trial. Br J Cancer 2007;97:152-161.

29 Karnon J, Delea T, Barghout V: Cost utility analysis of early adjuvant letrozole or anastrozole versus tamoxifen in postmenopausal women with early invasive breast cancer: the UK perspective. Eur J Health Econ 2008;9:171-183.

30 Hillner BE: Benefit and projected cost-effectiveness of anastrozole versus tamoxifen as initial adjuvant therapy for patients with early-stage estrogen receptor-positive breast cancer. Cancer 2004;101:1311-1322.

31 Locker GY, Mansel R, Cella D, Dobrez D, Sorensen S, Gandhi SK; ATAC Trialists' Group Cost-effectiveness analysis of anastrazole versus tamoxifen as primary adjuvant therapy for postmenopausal women with early breast cancer: a US healthcare system perspective. The 5-year completed treatment analysis of the ATAC ('Arimidex', Tamoxifen Alone or in Combination) trial. Breast Cancer Res Treat 2007;106:229-238.

32 Karnon J: Cost-effectiveness of letrozole, anastrozole and exemestane for early adjuvant breast cancer. Expert Rev Pharmacoecon Outcomes Res 2007;7:143-153.

33 Skedgel C, Rayson D, Dewar R, Younis T: Cost-utility of adjuvant hormone therapies with aromatase inhibitors in post-menopausal women with breast cancer: upfront anastrozole, sequential tamoxifen-exemestane and extended tamoxifenletrozole. Breast 2007;16:252-261.

34 Lux MP, Wöckel A, Benedict A, Buchholz S, Harbeck N, Kreienberg R, Kaufmann M, Beckmann MW, Jonat W, Hadji P, Distler W, Raab G, Tesch H, Weyers G, Possinger K, Schneeweiss A: Cost-effectiveness analysis of anastrozole versus tamoxifen in adjuvant therapy for early-stage breast cancer - a health-economic analysis based on the 100-month analysis of the ATAC trial and the German health system. Onkologie 2010;33:155-166.

35 Cuzick J: Primary endpoints for randomised trials of cancer therapy. Lancet 2008;371:2156-2158.

36 Seruga B, Tannock IF: Up-front use of aromatase inhibitors as adjuvant therapy for breast cancer: the emperor has no clothes. J Clin Oncol 2009;27:840842.

37 Karnon J, Kaura S: Updated survival-based analysis using inverse probability of censoring weighted analysis (IPCW) to estimate the cost-effectiveness of letrozole and anastrozole versus tamoxifen as adjuvant therapy in postmenopausal women with early breast cancer. J Clin Oncol 2010;28(suppl 15): $\operatorname{abstr} 656$.

38 Hershman DL, Shao T, Kushi LH, Buono D, Tsai WY, Fehrenbacher L, Kwan M, Gomez SL, Neugut AI: Early discontinuation and nonadherence to adjuvant hormonal therapy are associated with increased mortality in women with breast cancer. Breast Cancer Res Treat 2011;126: 529-537. 